\title{
Oxidation of caffeine by phosphate radical anion in aqueous solution under anoxic conditions
}

\author{
MARAM RAVI KUMAR and MUNDRA ADINARAYANA* \\ Department of Chemistry, Osmania University, Hyderabad 500 007, India \\ e-mail: mundra_adinarayana@usa.net
}

MS received 10 April 2000; revised 20 June 2000

\begin{abstract}
The photooxidation of caffeine in presence of peroxydiphosphate (PDP) in aqueous solution at natural $p \mathrm{H}(\sim 7.5)$ has been carried out in a quantum yield reactor using a high-pressure mercury lamp. The reactions were followed spectrophotometrically by measuring the absorbance of caffeine at $\lambda_{\max }(272 \mathrm{~nm})$. The rates of reaction were calculated under different experimental conditions. The quantum yields were calculated from the rates of oxidation of caffeine and the intensity of light at $254 \mathrm{~nm}$ which was measured by using peroxydisulphate solution as a standard chemical actinometer. The reaction rates of oxidation of caffeine by PDP increase with increase in [PDP] as well as with increase in light intensity, while they are independent of [caffeine]. The quantum yields of oxidation of caffeine by PDP are independent of [PDP] as well as light intensity. However, quantum yields of oxidation of caffeine by PDP increase with increase in caffeine concentration. On the basis of these experimental results and product analysis, a probable mechanism has been suggested in which PDP is activated to phosphate radical anions $\left(\mathrm{PO}_{4}{ }^{\circ-}\right)$ by direct photolysis of PDP and also by the sensitizing effect of caffeine. The phosphate radical anions thus produced react with caffeine by electron transfer reaction, resulting in the formation of caffeine radical cation, which deprotonates in a fast step to produce C8$\mathrm{OH}$ adduct radicals. These radicals might react with PDP to give final product 1,3,7trimethyluric acid and $\mathrm{PO}_{4}{ }^{-2-}$ radicals, the latter propagates the chain reaction.
\end{abstract}

Keywords. Oxidation of caffeine; phosphate radical anion; peroxydiphosphate.

\section{Introduction}

Caffeine is a naturally occurring purine base present in coffee, tea, cocoa and nuts. Because of the vast consumption of caffeine-containing beverages, research has focused attention on its physiological effects. It has been reported that a number of biochemical reactions in our body generate reactive oxygen species mainly comprising free radicals and excited states, capable of damaging crucial biomolecules. The major reactive oxygen species of interest in oxidative stress and radiation damage are viz., hydroxyl radical $\left.{ }^{\circ} \mathrm{OH}\right)$, superoxide $\left(\mathrm{O}_{2}{ }^{--}\right)$, hydrated electron $\left(e_{\mathrm{aq}}{ }^{-}\right)$, hydrogen peroxide $\left(\mathrm{H}_{2} \mathrm{O}_{2}\right)$, peroxyl radical ( $\left.\mathrm{ROO}^{\circ}\right)$ etc. are capable of damaging crucial biomolecules such as DNA, proteins and membrane lipids ${ }^{1,2}$. Most of the damage induced by radiation in biological systems is mediated by the products of radiolysis of water and their reactions. If these radicals are not effectively scavenged by the antioxidant defense system in the tissues, oxidative stress results ${ }^{3,4}$.

*For correspondence 
Caffeine has been reported ${ }^{4-7}$ to have significant abilities to scavenge highly reactive free radicals and excited states of oxygen and to protect crucial biological molecules against these species. Antioxidant ability of caffeine is similar to that of the established biological antioxidant glutathione and significantly much higher than that of ascorbic $\operatorname{acid}^{8}$.

Caffeine is a potent scavenger of hydroxyl radicals. It has been reported ${ }^{6}$ that the reaction rate constants of hydroxyl radical with caffeine is determined to be $6.9 \times 10^{9} \mathrm{~mol} \mathrm{dm}^{-3} \mathrm{~s}^{-1}$ in pulse radiolysis. Caffeine reaction with $\mathrm{OH}$ radicals generated by the Fenton reaction or by the reaction of $\mathrm{Cr}(\mathrm{V})$ with $\mathrm{H}_{2} \mathrm{O}_{2}$, and investigated by electron spin resonance (ESR) spin trapping technique shows that caffeine effectively scavenges $\mathrm{OH}$ radical with a rate constant of approximately $5.9 \times 10^{9} \mathrm{~mol} \mathrm{dm}^{-3} \mathrm{~s}^{-1}$ which is comparable with those of other efficient $\mathrm{OH}$ radical scavengers.

Telo and Vieira ${ }^{9}$ have studied the oxidation of caffeine by $\mathrm{SO}_{4}{ }^{-{ }^{-}}$and also by hydroxyl radicals in aqueous solution and 1,3,7-trimethyluric acid has been reported as the product of oxidation in both cases.

Free phosphate group is constantly released from nucleotides, polynucleotides and DNA during an aerobic metabolic process ${ }^{10}$. On exposure of ionizing radiation to aerobic biological systems, oxy radicals are produced and it is also possible that the phosphate group present in such systems might be converted to phosphate radical anion which further take part in other oxidative processes ${ }^{11}$. In this connection the study of oxidation of caffeine assumes significance as a scavenger of phosphate radical anions. Phosphate radical anions can be generated by the photolysis of peroxydiphosphate using a highpressure mercury lamp in a quantum yield reactor ${ }^{12,13}$. In this paper we report the results on the photooxidation of caffeine in presence of peroxydiphosphate in aqueous solution.

\section{Experimental}

Caffeine was purchased from Sigma and used as received. The solutions of caffeine were always prepared afresh using double distilled water. Lithium salt of peroxydiphosphate (PDP) was prepared by the electrolysis process ${ }^{14}$, and its solutions were prepared and standardized as reported by Kapoor et al ${ }^{15}$. Irradiations were carried out in a quantum yield reactor model QYR-20 using a high pressure mercury lamp. In general, intensity measurements were made using ferrioxalate actinometry, while the intensity at $254 \mathrm{~nm}$ was measured taking peroxydisulphate chemical actinometry as standard. All the experiments were carried out under anoxic conditions by degassing with $\mathrm{N}_{2}$ (purity 99.999\%) for $30 \mathrm{~min}$. In a typical reaction, caffeine and PDP solutions were degassed for 30min, then mixed, again degassed and the solution sealed with teflon tape before irradiation. The reaction mixture was taken in a specially designed $1 \mathrm{~cm}$-path length cuvette which is suitable both for irradiations in the reactor as well as for absorbance measurements. The absorbance measurements were made on a HITACHI UV-Vis spectrophotometer model 3410 . These measurements were made at the $\lambda_{\max }(272 \mathrm{~nm})$ of caffeine to follow the progress of the reaction between caffeine and phosphate radical anion. The reaction rates with respect to caffeine consumption were calculated from the plots of absorbance versus time (figure 1) using a computer program MicroCal Origin. The quantum yields of the reactions have been calculated from the rates and the calculated light intensity absorbed by PDP at $254 \mathrm{~nm}^{16}$. This is the wavelength at which peroxydiphosphate is activated to radical reactions. The light intensity absorbed by PDP was calculated using the following equation. 


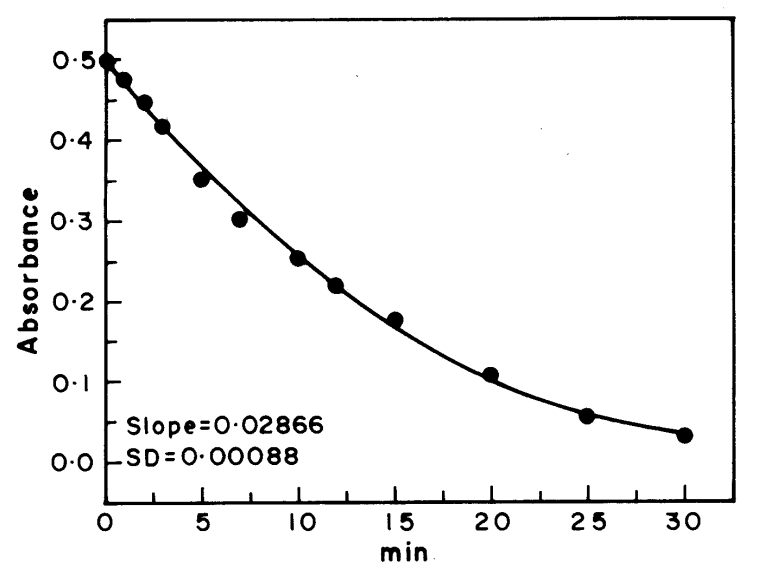

Figure 1. Photooxidation of caffeine in presence of peroxydiphosphate in aqueous anoxic conditions. Plot of absorbance vs time: $[\mathrm{PDP}]=5.0 \times 10^{-4} \mathrm{~mol} \mathrm{dm}^{-3}$, $\left[\right.$ caffeine] $=5.0 \times 10^{-5} \mathrm{~mol} \mathrm{dm}^{-3}$, temp. $=298 \mathrm{~K}$, light intensity $=7.98 \times 10^{14}$ quanta s $^{-1}$.

$$
I_{\mathrm{PDP}}=\left[\varepsilon_{\mathrm{PDP}}[\mathrm{PDP}] /\left(\varepsilon_{\mathrm{PDP}}[\mathrm{PDP}]+\varepsilon_{\text {caffeine }}[\text { caffeine }]\right)\right] I_{\mathrm{t}},
$$

$I_{\mathrm{PDP}}=$ The intensity of light absorbed by peroxydiphosphate, $I_{\mathrm{t}}=$ total intensity of light measured from peroxydisulphate actinometry, $\varepsilon_{\mathrm{PDP}}=$ The molar absorption coefficient of peroxydiphosphate at $254 \mathrm{~nm}\left(27 \mathrm{dm}^{3} \mathrm{~mol}^{-1} \mathrm{~cm}^{-1}\right), \quad \varepsilon_{\text {caffeine }}=$ The molar absorption coefficient of caffeine at $254 \mathrm{~nm}\left(6250 \mathrm{dm}^{3} \mathrm{~mol}^{-1} \mathrm{~cm}^{-1}\right)$.

The HPLC system used for analysis of products includes Shimadzu LC-10AT equipment with a dual piston-pump system, a solvent programmer and a Reodhyne injector model 7725 fitted with $20 \mu 1$ loop. A prepacked octadecylsilyl silica gel ODS hypersil column $25 \times 0.46 \mathrm{~cm}$, mean particle size $5 \mu \mathrm{m}$ was used. The column effluents were monitored at $280 \mathrm{~nm}$, using variable wavelength SPD-10A UV-Vis detector equipped with an $8 \mu \mathrm{l}$ flow cell and attached to a C-R7Ae plus chromatopac integrator. Samples were eluted with aqueous solutions containing 5\% (v/v) methanol and buffered with $10 \mathrm{mM} \mathrm{KH}_{2} \mathrm{PO}_{4}$ solution adjusted to $p \mathrm{H} 7 \cdot 0$. Before use the phosphate buffer was filtered through a millipore type HA $0.45 \mu \mathrm{m}$ membrane filter. All mobile phases were degassed using a vacuum pump. The solvent flow rate was kept constant at $1.0 \mathrm{ml} / \mathrm{min}$ and all the HPLC runs were carried out at ambient temperature.

\section{Results and discussion}

The photooxidation of caffeine in presence of peroxydiphosphate has been carried out in aqueous solution and the reaction rates of caffeine oxidation have been measured under different experimental conditions. An increase in [caffeine] at constant [PDP] and light intensity has no effect on the rate of oxidation of caffeine (table 1), whereas increase in [PDP] has been found to increase the reaction rate at constant [caffeine] and intensity of light (table1). The order of reaction with respect to [PDP] has been found to be unity (figure 2). The quantum yields of the reactions have been found to depend on [caffeine] while they are independent of both [PDP] and light intensity (tables 1 and 2). The irradiated aqueous solution of caffeine and PDP has been analysed in HPLC using UV- 
Vis detector. Two peaks were observed with retention times $13 \mathrm{~min}$ and $10.7 \mathrm{~min}$ in which $13 \mathrm{~min}$ corresponds to caffeine and the other at $10 \cdot 7$ min corresponds to $1,3,7$ trimethyluric acid (product of caffeine) which was further confirmed by an authentic sample (figure 3).

Table 1. Rates and quantum yields of oxidation of caffeine on photolysis of peroxydiphosphate (PDP) in presence of caffeine in aqueous solutions.

Incident light intensity $=7.98 \times 10^{14}$, quanta $\mathrm{s}^{-1}$, temp. $=298 \mathrm{~K}$

\begin{tabular}{|c|c|c|c|}
\hline $\begin{array}{l}10^{4} \times[\mathrm{PDP}] \\
\left(\mathrm{mol} \mathrm{dm}^{-3}\right)\end{array}$ & $\begin{array}{c}10^{5} \times[\text { caffeine }] \\
\left(\mathrm{mol} \mathrm{dm}^{-3}\right)\end{array}$ & 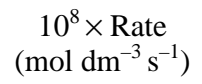 & $\begin{array}{c}\text { Quantum yield } \\
(\phi)\end{array}$ \\
\hline $5 \cdot 0$ & $1 \cdot 0$ & $3 \cdot 47 \pm 0 \cdot 22$ & $0 \cdot 329$ \\
\hline $5 \cdot 0$ & $3 \cdot 0$ & $3 \cdot 42 \pm 0 \cdot 17$ & $0 \cdot 817$ \\
\hline $5 \cdot 0$ & $5 \cdot 0$ & $4 \cdot 77 \pm 0 \cdot 15$ & $1 \cdot 83$ \\
\hline $5 \cdot 0$ & 10 & $3 \cdot 90 \pm 0 \cdot 18$ & $2 \cdot 90$ \\
\hline $1 \cdot 0$ & 10 & $0.770 \pm 0.12$ & $2 \cdot 79$ \\
\hline $3 \cdot 0$ & 10 & $2 \cdot 27 \pm 0 \cdot 87$ & 2.78 \\
\hline $5 \cdot 0$ & 10 & $3 \cdot 90 \pm 0 \cdot 18$ & $2 \cdot 90$ \\
\hline 10 & 10 & $7 \cdot 13 \pm 0 \cdot 65$ & $2 \cdot 74$ \\
\hline
\end{tabular}

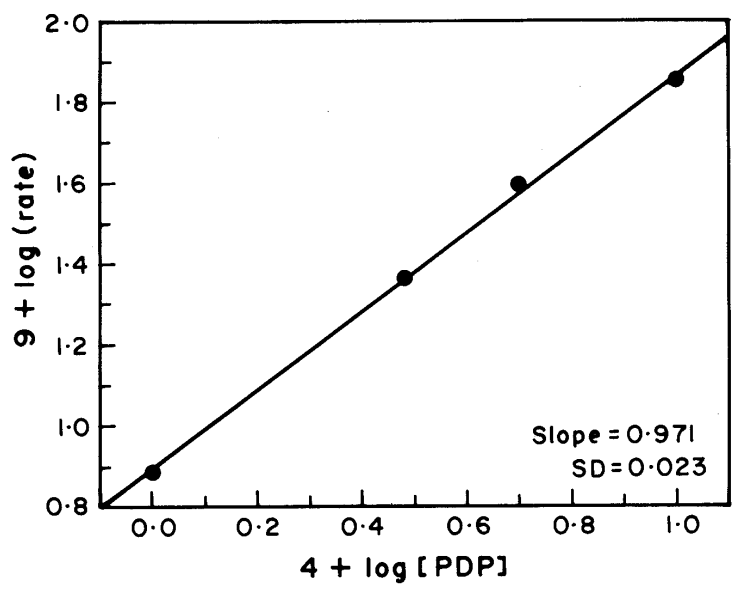

Figure 2. Order of $[\mathrm{PDP}]$ in the photooxidation of caffeine in presence of peroxydiphosphate in aqueous solution. Plot of $9+\log$ (rate) vs $4+\log$ [PDP]: [caffeine] $=1.0 \times 10^{-4} \mathrm{~mol} \mathrm{dm}^{-3}$, temp. $=298 \mathrm{~K}$, light intensity $=7.98 \times 10^{14}$ quanta s$^{-1}$.

Table 2. Effect of light intensity on the rate of oxidation of caffeine on photolysis of peroxydiphosphate in presence of caffeine in aqueous solution.

$[\mathrm{PDP}]=5.0 \times 10^{-4} \mathrm{~mol} \mathrm{dm}{ }^{-3}, \quad[\mathrm{caffeine}]=1.0 \times 10^{-4} \mathrm{~mol} \mathrm{dm}^{-3}, \quad$ temp. $=298 \mathrm{~K}$, incident light intensity $=7.98 \times 10^{14}$ quanta $^{-1}$

\begin{tabular}{|c|c|c|}
\hline $10^{-14} \times$ Intensity (quanta $\mathrm{s}^{-1}$ ) & $10^{8} \times$ Rate $\left(\mathrm{mol} \mathrm{dm}^{-3} \mathrm{~s}^{-1}\right)$ & Quantum yield $(\phi)$ \\
\hline 7.980 & $3 \cdot 90 \pm 0 \cdot 18$ & $2 \cdot 90$ \\
\hline $11 \cdot 73$ & $4 \cdot 18 \pm 0 \cdot 17$ & $2 \cdot 12$ \\
\hline $14 \cdot 64$ & $5 \cdot 20 \pm 0 \cdot 28$ & $2 \cdot 11$ \\
\hline
\end{tabular}




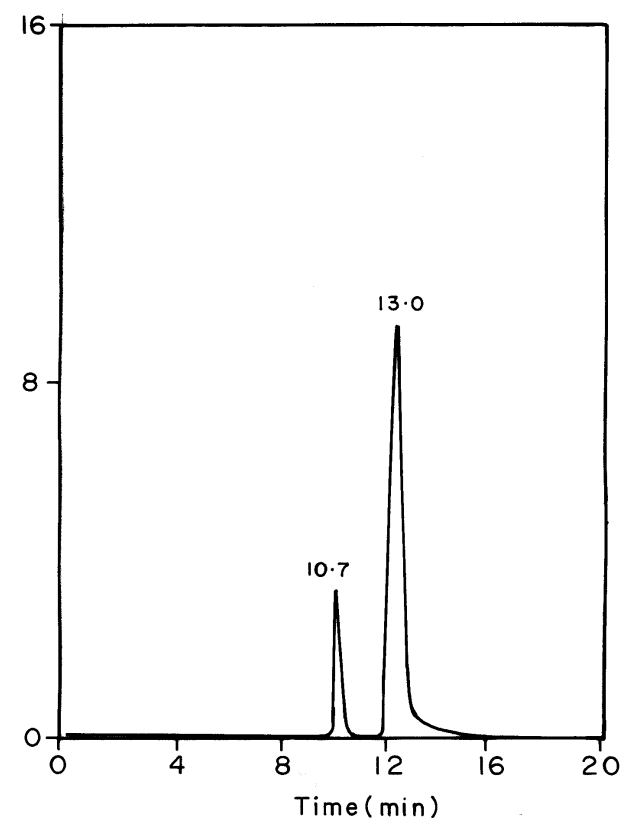

Figure 3. The optical chromatogram at $280 \mathrm{~nm}$ of reaction mixture $(0.5 \mathrm{mM}$ PDP and $0.1 \mathrm{mM}$ caffeine) irradiated for $50 \mathrm{~min}$. Peaks at $10.7 \mathrm{~min}$ and $13.0 \mathrm{~min}$ correspond to 1,3,7-trimethyluricacid and caffeine respectively.

It has been reported that $\mathrm{OH}$ radicals attack purines, viz., xanthine, isocaffeine, guanine and adenine at $\mathrm{C} 8$-position ${ }^{17-20}$. The product of oxidation of caffeine by $\mathrm{OH}$ radicals has been reported to be 1,3,7-trimethyluric acid formed via $\mathrm{C} 8-\mathrm{OH}$ adduct radicals. Sulphate radical anion is known to react with purines by electron transfer, producing one electron oxidised species as primary product i.e. radical cation. Oxidation of caffeine and isocaffeine by $\mathrm{SO}_{4}{ }^{--}$has been reported to follow similar mechanism. The products of oxidation of caffeine and isocaffeine have been found to be 1,3,7trimethyluric acid and 1,3,9-trimethyluric acid respectively which were proposed to be formed via $\mathrm{C} 8-\mathrm{OH}$ adduct radical.

The phosphate radical anion which is produced on photolysis of peroxydiphosphate in the initiation step is isostructural and isoelectronic with sulphate radical anion $\left(\mathrm{SO}_{4}{ }^{-}\right.$) and it is expected to react in a similar fashion. The light intensity has no effect on the quantum yields indicating that it might be involved mainly in the activation of PDP to phosphate radical anion in the initiation step. Since the oxidation of caffeine is not observed in the absence of PDP on shining the light, the increase in the quantum yield of caffeine oxidation with increase in [caffeine] (table 1) suggest that the excited state of caffeine might be acting as a sensitizer to transfer energy to PDP to produce phosphate radical anions in a fast step. The lifetime of the excited singlet ${ }^{21}$ state of caffeine is of the order of a few picoseconds while the life time of the excited triplet state is $4.5 \mu \mathrm{s}^{22}$. Further, in the caffeine system the yields of intersystem crossing has been reported to be quite high, and therefore the excited triplet concentration of caffeine would be higher during the photolysis process in our system. It is therefore proposed that in the 
sensitization of PDP by caffeine in the secondary step, the triplet state of caffeine may be involved. The reaction rates are found to be independent of [caffeine] suggesting that phosphate radical anion might react with caffeine in a fast step. The quantum yields of oxidation of caffeine with $\mathrm{PO}_{4}{ }^{2-}$ are found to be more than one indicating the involvement of a chain reaction. The increase in the reaction rates of caffeine oxidation with increase in [PDP] suggests that PDP might be reacting with the transient $\mathrm{C} 8-\mathrm{OH}$ adduct radicals to give the final product and the phosphate radical anion which could propagate the chain reaction. The reaction mechanism is presented in scheme 1 .

\section{Conclusions}

The oxidation product 1,3,7-trimethyluric acid identified by HPLC analysis and the rates and quantum yields of oxidation of caffeine by $\mathrm{PO}_{4}{ }^{-2-}$ suggest that $\mathrm{PO}_{4}{ }^{-2-}$ attacks at $\mathrm{C} 8$ position of caffeine leading to $\mathrm{C} 8-\mathrm{OH}$ radical adduct which propagates the chain reaction by reacting with PDP giving the final product and $\mathrm{PO}_{4}{ }^{2-}$.

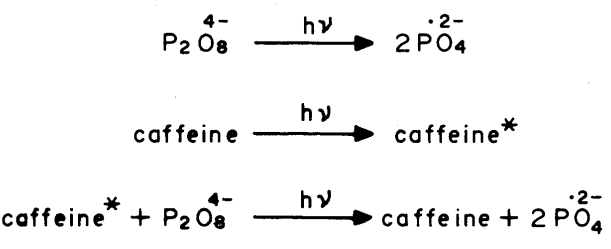

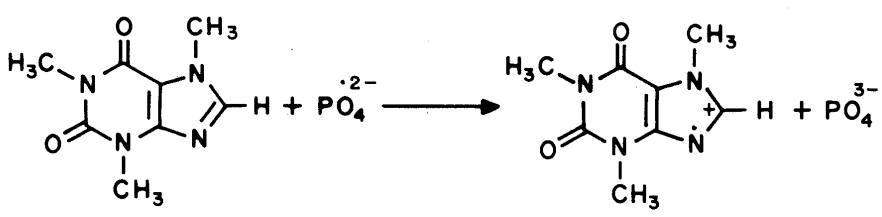
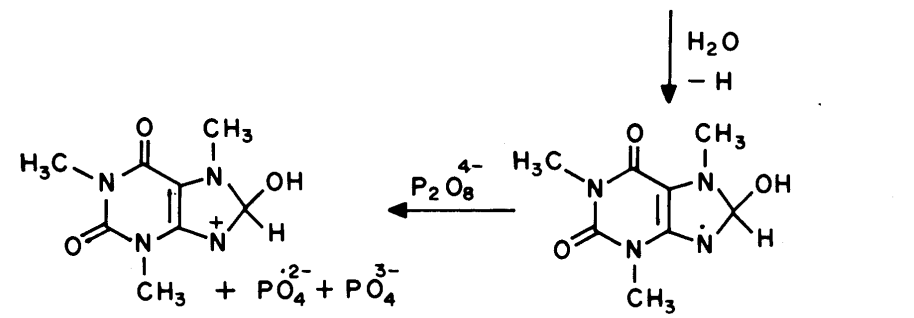<smiles>Cn1c(=O)c2c(nc(O)n2C)n(C)c1=O</smiles>

Scheme 1. 


\section{Acknowledgements}

The authors thank Prof P Jayaprakash Rao for helpful discussions and Department of Botany, Osmania University for providing HPLC facilities. MR is thankful to the University Grant Commission, New Delhi, for a fellowship.

\section{References}

1. Green A, Prager, Stoudt P M and Murray D 1992 Int. J. Radiat. Biol. 61465

2. Yukawa O, Miyahara M, Shiraishi N and Nakazawa T 1985 Int. J. Radiat. Biol. 48107

3. Seis H 1986 Angew. Chem., Int. Ed. Engl. 251058

4. Devasagayam T P A and Kesavan P C 1996 Indian J. Exp. Biol. 34291

5. Devasagayam T P A, Kamat J P, Harimohan and Kesavan P C 1996 Biochem. Biophys. Acta 128263

6. Kesavan P C and Powers E L 1985 Int. J. Radiat. Biol. 48223

7. Kesavan P C 1992 Curr. Sci. 62791

8. Kesavan P C and Sarma L 1995 In Sub cellular biochemistry, vol. 25: Ascorbic acidBiochemistry and biomedical cell biology (New York: Plenum) 407

9. Telo P J and Vieira A J S C 1997 J. Chem. Soc., Perkin. Trans 21755

10. Behrens G, Koltzenberg G and Schulte Frohlinde D 1982 Z. Naturforsch. C37 1205

11. Steenken S and Goldbergerova 1998 J. Am. Chem. Soc. 1203928

12. Ravi Kumar M and Adinarayana M 1998 Indian. J. Chem. A37 346

13. Ravi Kumar M, Thirupathi Rao M and Adinarayana M 2000 Indian J. Biochem. Biophys. 37 13

14. Creaser I I and Edwards J O 1972 Top. Phosphorus Chem. 7379

15. Kapoor S, Sharma P D and Gupta Y K 1975 Talanta 22765

16. Ravi Kumar M, Thirupathi Rao M and Adinarayana M 2000 Indian J. Chem. A39 (in press)

17. Santamaria J, Pasquier C, Ferradini and Pucheault J 1984 Adv. Exp. Med. Biol. A167 185

18. Vieira A J C S and Steenken S 1996 J. Chim. Phys. 93235

19. Vieira A J C S and Steenken S 1990 J. Am. Chem. Soc. 1126986

20. Vieira A J C S, Candeias L P and Steenken S 1993 J. Chim. Phys. 90881

21. Murgida D H, Bilmes G M and Erra-Balsells R 1996 Photochem. Photobiol. 64777

22. Kasama K, Takematsu A and Aral S 1982 J. Phys. Chem. 862420 